
\title{
$\angle S$ Research Square \\ The Wear Detection of Mill-Grinding Tool Based on Acoustic Emission Sensor
}

\author{
Wuzhen Huang \\ Huaqiao University \\ Yuan Li ( $\square$ liyuan@hqu.edu.cn ) \\ Huaqiao University \\ Xian Wu \\ Huaqiao University \\ Jianyun Shen \\ Huaqiao University
}

\section{Research Article}

Keywords: Wear detection, Zirconia ceramic, Mill-grinding tool, Acoustic emission

Posted Date: November 9th, 2021

DOI: https://doi.org/10.21203/rs.3.rs-1052270/v1

License: (9) This work is licensed under a Creative Commons Attribution 4.0 International License. Read Full License

Version of Record: A version of this preprint was published at The International Journal of Advanced Manufacturing Technology on April 7th, 2022. See the published version at https://doi.org/10.1007/s00170-022-09058-7. 


\section{Abstract}

The monitoring of tool wear plays an important role in improving the processing efficiency and reducing the production cost of enterprises. This paper is focused on the detection of electroplated diamond millgrinding tools by using the acoustic emission sensor. The wear stages of mill-grinding tools are divided into three parts, namely initial wear stage, normal wear stage, and severe wear stage. The characteristic parameter method and the waveform analysis method are applied to analyze the acoustic emission signals. The wear characteristics of the tool and workpiece in different wear stages are observed and analyzed. The results indicate that the acoustic emission waveform is relatively stable in the initial wear stage, and the continuous acoustic emission signal is dominated. Moreover, the diamond abrasive grains are mainly worn and slightly broken in the normal wear stage, and there are some pits on the machined workpiece surface after the initial wear stage. In the severe wear stage, most of the abrasive grains are broken or broken in a large area, and there are burst acoustic emission signals in the waveform.

\section{1.introduction}

In recent years, acoustic emission technology, as a mature non-destructive testing method, has been more and more widely used in many fields, such as various industries in national defense and the economy [1]. With the continuous improvement of acoustic emission technology, it has also been applied in the field of mechanical structures $[2,3]$.

In the aspect of mechanical equipment operating condition and fault diagnosis identification, Faris et al. [4] explored the characteristics of acoustic emission and vibration signals in diagnosing a bearing defect in the planetary gearbox. What's more, the application of acoustic emission testing technology to fatigue and crack detection of components can effectively predict other types of faults such as crack initiation and propagation. He et al. [5] studied the noise interference in the acoustic emission signal of rotor crack, and he also analyzed the acoustic emission signal characteristics of propagation under different working conditions by using wavelet packet technology. Zhang et al. [6] used the acoustic emission detection technology to record the acoustic emission signals of rail defects. Meanwhile, the wavelet transform and Shannon entropy were employed to process the signals. When monitoring the micro-fracture process of fissured rocks, a series of biaxial compression tests was carried out on sandstone specimens with two parallel filled flaws exploiting the acoustic emission (AE) [7]. By analyzing the acoustic emission signal data, Elforjani et al. [8] investigated the crack propagation, subsurface crack initiation, and location of natural defects in rolling bearings. In the field of machining, metal burn is a common problem. Different degrees of metal burns will cause different degrees of damage to related components. Gao et al. [9] used an infrared thermal imager and acoustic emission sensor to explore the relationship between the combustion degree of 1045 steel and acoustic emission signal, which provided guidance for metal combustion detection.

As for the process of mechanical processing, in addition to metal burns, tool wear also plays a very important role in the control of machining quality. Therefore, the subject of machining tool wear has 
become a research focus of many scholars. Liang et al. [10] conducted a tool wear experiment on dry cutting titanium alloy Ti-6Al-4V, and observed the tool wear characteristics, and analyzed the tool wear mechanism. However, many scholars directly explore the wear of tools through the wear experiments of machining tools, such as end-face milling [11] drilling [12], turning [13], grinding [14] and other tool wear experiments. Combined with the wear conditions of tools, the wear mechanism of machining tools is analyzed. Through sawing experiments, Zhou et al. [15] comprehensively analyzed and compared the wear characteristics of multi-blade combination saw with different diameters in the process of processing granite combined with the load model, the blade height of diamond grains and the wear morphology of metal substrate.

Many scholars have explored the wear mechanism of the tools [16]. However, the deformation of the workpiece, chip formation and the friction between the tool and the workpiece surface is closely related to the force signal in the machining process [17]. Therefore, many scholars have further used the force sensor to monitor the wear of the tool while studying the mechanism. Luo and other scholars [18] studied the worn form of diamond grinding wheel and the change of grinding force ratio by Kistler 9257B dynamometer. Ma et al. [19] used the Kistler 9374C force sensor to monitor tool wear during high speed grinding of SiC workpiece, and they used the time domain value of force signal to define the stability of the grinding process. Tool wear will cause certain mechanical vibrations, so the acceleration sensor can also be used to monitor the tool wear. Wafaa et al. [20] applied a three-dimensional acceleration sensor to collect the vibration signal of turning process, and the average power of the vibration signal was used as the characteristic value to judge the tool wear state. As a modern non-destructive testing technology, acoustic emission monitoring technology started from a German researcher of Kaiser in the 1950s, and it was gradually introduced into the field of mechanical processing by scholars [21]. The acoustic emission detection technology has been applied in some metal materials and composite materials, and gradually, it has been widely used in the fields of mechanical equipment fault diagnosis, component crack detection and fluid leakage. At present, few scholars are studying the wear monitoring of diamond mill-grinding tools. In addition, the acoustic emission sensor has strong adaptability and is not affected by the vibration of machine tools. Therefore, this paper selects the acoustic emission sensor to monitor the wear state of tools for mill-grinding zirconia ceramics.

The acoustic emission signal waveform characteristics of diamond mill-grinding tools in different wear conditions are analyzed and compared in this paper, and the eigenvalues used to characterize different wear stages are extracted. The wear characteristics of mill-grinding tools in different wear stages are tracked and the morphology of workpiece are observed and described in detail, and the influence of millgrinding tool wear on acoustic emission signal and workpiece surface quality is analyzed.

\section{2.experimental Setup}

\subsection{Material and equipment}


The electroplated diamond mill-griding tools produced by Shenzhen Changxing Technology Co. LTD are used in the experiment. The grain size of diamond is $120 \#$, and the mean grain size of diamond abrasive grains is about $106-120 \mu \mathrm{m}$. The diameter of the mill-griding tool is $10 \mathrm{~mm}$. In this experiment, the workpiece material is zirconia ceramic with the size of $150 \times 80 \times 10 \mathrm{~mm}$, which is widely used in $5 \mathrm{G}$ highend ceramic mobile phone backplane. The reason is that the backplane made of zirconia ceramic has many excellent features such as no signal interference and good wear resistance [22]. However, the zirconia ceramics have high material hardness, high brittleness, and other mechanical properties. The other mechanical properties of zirconia were listed in Table1.

Table 1 Mechanical properties of zirconia ceramic.

\begin{tabular}{|lll|}
\hline Properties & Unit & Value \\
\hline Density & $\mathrm{g} / \mathrm{cm}^{3}$ & 6.05 \\
\hline Vicher Hardness & $\mathrm{HV}_{0.5}$ & 1175 \\
\hline Modulus of Elasticity & $\mathrm{Gpa}$ & 200 \\
\hline Fracture toughness & $\mathrm{Mpa} \cdot \mathrm{m}^{1 / 2}$ & 8 \\
\hline
\end{tabular}

\subsection{Monitoring equipment}

This experiment mainly used a PC-based acoustic emission (AE) data acquisition system, and a force data acquisition system was combined to assist in monitoring the wear of diamond tools in the millgriding process. The generation of acoustic emission signal is due to the change in the internal structure of the material, which causes the sudden redistribution of the internal stress of the material, so that the mechanical energy is transformed into acoustic energy, thus generating elastic waves. In the mill-griding process of zirconia ceramics, there are plenty of acoustic emission sources in the mill-griding area, such as the chip formation of zirconia ceramic, the chip breakage of zirconia ceramic, the elastic deformation of zirconia material, sliding friction or plastic deformation of zirconia ceramic. Along with the diamond grains wear out, the acoustic emission source may also come from the cracks of diamond grains and the separation of diamond grains. In addition, the acoustic emission sensor has a high-sensitivity detection and generally collects a wide signal frequency band, which is conducive to avoiding the low-frequency area of noise interference. Therefore, the acoustic emission system is suitable for detecting the wear state of diamond mill-griding tools.

For the construction of the acoustic emission signal acquisition platform in the mill-grinding process, it is mainly composed of acoustic emission sensors, amplifiers, acquisition cards, and the chassis of acoustic emission. In this experiment, the R15-alpha resonant acoustic emission sensor was employed. In order to fill the tiny gaps between the contact surfaces of the acoustic emission sensor, and reduce its energy loss, the vaseline was selected as the couplant of the acoustic emission sensor before the experiment. Then the acoustic emission sensor was installed and adjusted with a special magnetic base, so that it was fixed in a relatively close position to the mill-grinding area. 
The signal input end of the universal 2/4/6 preamplifier is connected with the acoustic emission sensor. The signal received from the sensor is amplified, and then transmitted to the $\mathrm{PCl}-2$ acoustic emission acquisition card through the cable. The acquisition card inserts into the corresponding card slot reserved in the acoustic emission chassis of Micro-II produced by Physical Acoustics Corporation (PAC). The original signal data is saved through the AEwin software, and the signal can be displayed on the screen in real time. At the same time, the original acoustic emission signal can also be exported offline for postprocessing. The specific parameters of the acoustic emission sensor are shown in Table2. To ensure the accuracy of $A E$ acquisition, a pencil lead-breaking experiment was carried out before the mill-grinding process. And the coupling of the acoustic emission sensor and the influence of environmental noise on the signal acquisition was determined through the experiment. According to the results of the leadbreaking procedure, the threshold values of the acoustic emission signal was set to $60 \mathrm{~dB}$. The amplification factor is $20 \mathrm{~dB}$. The sampling rate of the acoustic emission signal is $1 \mathrm{MHz}$.

Table2 Detailed parameters of R15-alpha resonant acoustic emission sensor

Table2 Detailed parameters of R15-alpha resonant acoustic emission sensor

\begin{tabular}{|c|c|c|}
\hline Properties & Unit & Value \\
\hline Peak Sensitivity, Ref V/ $\mu$ bar & $\mathrm{dB}$ & -63 \\
\hline Operations frequency range & $\mathrm{kHz}$ & $50 \sim 400$ \\
\hline Resonant Frequency & $\mathrm{kHz}$ & 150 \\
\hline Temperature range & ${ }^{\circ} \mathrm{C}$ & $-65 \sim 175$ \\
\hline Weight & $\mathrm{g}$ & 34 \\
\hline
\end{tabular}

\subsection{Experimental procedure}

The wear platform of mill-grinding tool was built in the MORI DMU 505 -axis machining center, and the diamond tool wear experiments were conducted on the platform. The acoustic emission monitoring system was used to collect the mill-grinding process signal for the full cycle of the tool life. Specifically, the zirconia ceramic workpiece was glued to the pre-designed fixture with paraffin wax, and the ceramic workpiece was pre-grinded with diamond wheel to ensure its flatness preliminarily. Then, it was clamped by the general fixture. By using a dial indicator and combined with the adjustment function of the fiveaxis rotation around the $y$-axis, the leveling work was accomplished, so that the flatness range of the zirconia ceramics processed by each mill-grinding process is within $5 \mu \mathrm{m}$. Then, the rotating cutting force dynamometer (RCD,9170A) of Kistler and the acoustic emission system were installed and debugged to record the force signals and acoustic emission signals of mill-grinding in real time. The force measuring system is mainly used to assist tool setting and preliminarily judge the wear state of diamond tools in the mill-grinding process. The specific test platform is shown in Fig.1. 
According to the actual production parameters of the enterprise, combined with the actual test conditions, the fixed mill-grinding machining parameters of $S=8000 \mathrm{rpm}, a_{p}=15 \mu \mathrm{m}$, and $v f=200 \mathrm{~mm} / \mathrm{min}$. The whole wear experiment of mill-grinding processing did not use cutting fluid. In order to further observe the wear of diamond mill-grinding tools, the ultra-depth-of-field electron microscope of KEYENCE VHX-1000 was used to track and monitor the wear stages of mill-grinding tools. For the surface morphology of zirconia ceramic workpieces in different wear stages, the optical 3D profilometer (Zygo NewView 7300) and the desktop tungsten filament scanning electron microscope (JEOL JSM-IT500) were used for observations respectively.

\section{Results And Discussion}

In this chapter, different wear stages of the acoustic emission signals, as well as the mill-grinding tools and zirconia ceramic workpieces have been analyzed separately. In general, the acoustic emission signal methods of processing and analysis mainly include the characteristic parameter method and the waveform analysis method [23]. In order to analyze and compare the main characteristics of different wear stages, this section mainly uses the amplitude characteristic parameters of the acoustic emission signal in the mill-grinding process. For the waveform of acoustic emission signal, the fast Fourier transform (FFT) method $[24,25]$ and time-frequency domain wavelet packet analysis method [26] is used to analyze the acoustic emission signal of different wear stages in the mill-grinding process. Furthermore, the wear characteristics and mechanism of the diamond mill-grinding tools in different wear stages and their effect on the zirconia ceramic workpieces have also be analyzed. The results will be discussed in each section.

\subsection{The analysis of sensor signals}

The research on force signals are relatively mature at present, and its validity has been verified. Therefore, the dynamometer was selected as the index sensor to provide convenience for the preliminary construction of monitoring the mill-grinding tools wear state. According to the characteristics of millgrinding force signals in different wear stages and the diamond abrasive wear of mill-grinding tools, the wear stages of diamond tools in this paper are divided into three parts, namely initial wear stage, normal wear stage, and severe wear stage. The acoustic emission waveform is relatively stable in the initial wear stage, and the continuous acoustic emission signal is dominated. In normal wear stage, the amplitude of the acoustic emission signal gradually increases in the stable processing area. whereas, there are burst acoustic emission signals in the waveform, and most of the abrasive grains are broken or broken in a large area in the severe wear stage. In this section, the further analysis of the acoustic emission signals in different wear stages is carried out.

The characteristic parameter of acoustic emission signal amplitude refers to the maximum amplitude of acoustic emission signal waveform during each impact. Theoretically, when the acoustic emission sensor output $1 \mu \mathrm{V}$ is defined as $0 \mathrm{~dB}$, the amplitude of original signal collected by the acoustic emission system 
is $V_{A E}$ (unit: $\mu \mathrm{V}$ ), and the conversion formula for the amplitude of the acoustic emission signal $d_{A E}$ is as follows:

$$
\mathrm{dB}_{\mathrm{AE}}=20\left(\operatorname{lgV}_{\mathrm{AE}} / 1 \mu \mathrm{V}\right)
$$

In the process of mill-grinding, the duration of 1.024s is taken as the impact point of acoustic emission signal in different wear stages, and the distribution of its amplitude over time is shown in Fig. 2 . The approximate range of cut in and cut out areas can be judged, as shown in the dotted box in the figure above. The stable stage of mill-grinding at different wear stages is mainly between 15 to 33 seconds. In the initial wear stage, the acoustic emission signal of mill-grinding process shows a relatively stable state, and its amplitude is about $95-100 \mathrm{~dB}$. While in the normal wear stage, its amplitude distribution is more scattered than that in the initial wear stage, and its average amplitude is around 100-105 dB. In this stage, the amplitude of local impact point fluctuates. The reason is that some diamond grains on the millgrinding tool are broken, and the new mill-grinding edges will gradually appear, resulting in a smaller acoustic emission amplitude of the partial impact point. At the same time, most of the diamond abrasive grains gradually wear with the accumulation of mill-grinding distance, so the amplitude increases to a certain extent compared with the initial wear stage. In the severe wear stage, the distribution of acoustic emission signal amplitude is $108-112 \mathrm{~dB}$ or so, and the position on the scatter graph is higher than that of the normal wear stage and the initial wear stage.

In order to further analyze and extract the waveform characteristics of acoustic emission signals in millgrinding process under different wear conditions, the acoustic emission waveform signals of initial wear stage, normal wear stage and severe wear stage are selected for processing respective. Because the generation rate of the acoustic emission signal is changeable, some scholars divide the acoustic emission signal into burst type and continuous type [27].

The time domain waveforms of acoustic emission signals in different wear stages are shown in the Fig. 3. Under the experimental conditions described in this paper, the acoustic emission signals of diamond tool in the initial wear stage can be regarded as continuous acoustic emission signals. With the continuous wear of diamond grains, the burst type acoustic emission signals appear in the normal wear stage, and the probability of burst type acoustic emission signal increases in the severe wear stages.

It can be seen from the time-domain waveform that the voltage value of the acoustic emission timedomain signal increases to a certain extent with the continuous wear of the mill-grinding tool. The acoustic emission signals of mill-grinding process in different wear stages are analyzed, and the frequency domain diagrams are obtained by using fast Fourier transform respectively [28], as shown in the Fig. 4.

According to the frequency spectrum comparison of acoustic emission signals in different wear stages above, it can be seen that the amplitude of the acoustic emission signal spectrum gradually increases 
with the continuous wear of the electroplated diamond mill-griding tools in the low-frequency band region of $0-1 \times 10^{5} \mathrm{~Hz}$. Nevertheless, in the region of $1 \times 10^{5}-2 \times 10^{5} \mathrm{~Hz}$, the amplitude of the frequency domain decreases with the increase of wear degree of diamond tools. When the frequency range is greater than $2 \times 10^{5} \mathrm{~Hz}$, the average amplitude of the acoustic emission signal in the initial wear stage is reduced to a certain extent compared with the other two stages.

As for the analysis results of the time domain and frequency domain, it can be obtained that the burst type and continuous type acoustic emission signals in the mill-grinding process are concentrated in different frequency bands. To further confirm the specific distribution of the burst type and continuous type acoustic emission signals in the time domain and frequency domain, it is necessary to analyze the original signal. Furthermore, the frequency domain segment of acoustic emission signal is analyzed, so the time-frequency domain analysis tool is selected to decompose the acoustic emission signals in different wear stages during the mill-grinding process. Although the traditional discrete wavelet transform provides flexible time-frequency resolution, it has a lower resolution in the high-frequency region.

Therefore, the acoustic emission signal is analyzed by wavelet packet transform (WPT) in this paper [29].

By comparing the characteristics of different wavelet basis functions, the acoustic emission signals of different wear stages in the mill-grinding process are decomposed into three layers by using the fourthorder Daubechies (db4) wavelet basis functions respectively. Then the signals of each stage are evenly divided into eight frequency bands. And the signal length of each frequency band is $1 / 8$ of the original signal. Finally, the wavelet packet reconstruction is carried out for each frequency band after decomposition, and the amplitude spectrum and the energy ratio of each frequency band are calculated. The comparison chart of wavelet packet energy ratio in each frequency band is shown in Fig. 5 .

Table 3

The percentage of wavelet packet energy in each frequency band

\begin{tabular}{|llll}
\hline Frequency range/KHz & Initial wear stage/\% & Normal wear stage/\% & Severe wear stage/\% \\
\hline $0-125$ & 18.73006 & 50.85412 & 70.58783 \\
\hline $125-250$ & 39.44957 & 36.18317 & 22.93493 \\
\hline $250-275$ & 2.44126 & 0.64694 & 0.35606 \\
\hline $275-500$ & 32.69444 & 11.3438 & 5.64838 \\
\hline $500-625$ & 0.09263 & 0.00911 & 0.00515 \\
\hline $625-750$ & 0.66082 & 0.12017 & 0.06177 \\
\hline $750-875$ & 3.22077 & 0.39602 & 0.18764 \\
\hline $875-1000$ & 2.71045 & 0.44667 & 0.21825 \\
\hline
\end{tabular}

For the different wear stages of diamond mill-grinding tools, the energy ratio of each reconstructed frequency band is shown in the Table 3. In the first frequency band, that is, in the frequency band of 0-125 
$\mathrm{kHz}$, the proportion of energy increases with the deterioration of diamond tools, from $18.73 \%$ of the initial wear increase to $70.59 \%$ of the later wear, which increases by about 3.77 times. In the $750-875 \mathrm{kHz}$ frequency band, the energy ratio of the acoustic emission signal in the three wear stages is $3.22 \%, 0.40 \%$, and $0.19 \%$, respectively, and the energy ratio in the initial wear stage is 8.05 times higher than that in the normal wear stage. As for the energy proportions of the remaining frequency bands, the proportion of energy presents a certain downward trend with the constant wear of mill-grinding tools.

\subsection{The characteristics of mill-gridding tool and workpiece}

With the increasing removal volume of zirconia ceramic materials, the number of wear diamond grains on the mill-grinding tool is gradually increasing in the selected area, and the wear degree of tool is also exacerbating, as shown in Fig. 6.

There is little difference of the grains in the selected area between the initial wear stage and the state without processing. This phenomenon is also consistent with the fact that the acoustic emission signal is relatively stable in the initial wear stage; In the normal wear stage, some of the diamond abrasive grains in the selected area are micro-fractured, and most of the diamond abrasive grains are mainly wear and tear; A worn belt is formed near the edge area of the diamond mill-grinding tool in the severe wear stage. What's more, most diamonds abrasive grains in this area are fracture, broken in large areas, or semibroken. The wear zone is mainly due to the fact that the undischarged zirconia ceramic powder is attached to the diamond abrasive grains during the process. With the decrease of the height for the diamond grains, there is a relative movement between the ceramic powder and the electroplating layer of the mill-grinding tool in this process. The friction between them aggravates the wear of the diamond millgrinding tools, which makes most of the diamond grains passivated or even invalid. So as to verify its wear state, the zirconia ceramic workpieces processed in different wear stages were selected in this paper. The surface morphology was detected by the optical 3D profilometer and scanning electron microscope, as shown in Fig. 7.

In the initial wear stage, some of the diamond grain protrusion height is comparatively high. Therefore, these diamond grains participate in the processing under a fixed cutting depth, leaving regular scratches on the surface of the processed zirconia ceramic workpiece, and the phenomenon of plastic side flow can be seen in the microstructure. The height data on the scratches were extracted by using the optical 3D profilometer, there are about 11 wave peaks and the length of the sample is $0.283 \mathrm{~mm}$ in the Fig. 7(a), therefore the difference between adjacent wave peaks is about $0.026 \mathrm{~mm}$, which is almost equal to the feed per revolution of the spindle $d_{s}=200 / 8000=0.025 \mathrm{~mm} / \mathrm{r}$. As shown in Fig. 7 (b) and (c), there are pits on the surface of the processed workpiece in the normal wear stage and the severe wear stage. In terms of the normal wear stage, the plastic side flow of the zirconia ceramics is slipped, accumulated, and fractured, which is also coincided with the burst type of the acoustic emission signal. What's more, in the severe wear stage, there is a scaly-like uniform crack formation in the deep part of the pit. This is because the diamond grains involved in the processing have been blunt in this wear stage, and their processing ability has decreased, thus affecting the quality of the machined surface. 


\section{Conclusion}

This paper presents an experimental study on the tool wear in mill-grinding of zirconia ceramic with the electroplated diamond mill-grinding tool. In the mill-grinding process, the variation of acoustic emission characteristic parameters and acoustic emission waveform characteristics in different wear stages are analyzed. Furthermore, an ultra-depth-of-field microscope is used to track and detect the mill-grinding tools. The desktop scanning electron microscope and the optical 3D profilometer are used to observe the surface morphology of the machined workpiece. And the effect of the tool wear is analyzed as well. Main conclusions from the performed research could be drawn as follows:

1. In the initial wear stage, the amplitude of the acoustic emission signal during the mill-grinding process is concentrated around $98.55 \mathrm{~dB}$. And the waveform signal is relatively stable. At this stage, the distance between two adjacent scratches on the processed workpiece surface is about $0.0234 \mathrm{~mm}$, which is almost consistent with the feed per revolution of the spindle. It can be seen from the morphology obtained by the scanning electron microscope that the phenomenon of plastic side flow appeared on the surface of the zirconia ceramic workpiece in this stage.

2. In the normal wear stage, the amplitude of the acoustic emission signal in the stable processing area is about $102.23 \mathrm{~dB}$. Generally speaking, the distribution of the amplitude in this stage is more scattered than that in the initial wear stage. The abrasive grains on diamond mill-grinding tools are mainly wear and tear, and a small part of the grains are slightly broken. Compared with the initial wear stage, the surface quality of the processed workpiece has obvious scratches and pits, and the plastic side flow of zirconia ceramic is slipped, accumulated and fractured, causing brittle fracture on the processed surface.

3. In the severe wear stage, the average amplitude of the acoustic emission signal is approximately $111.21 \mathrm{~dB}$. In this stage, the burst type acoustic emission signal occurred in the waveform, which is also corresponding to the fracture or failure of most abrasive grains on diamond mill-grinding tools. The reason is that the machining ability of the tool decreases with the dullness and failure of the diamond abrasive grains, which results in the scaly-like uniform crack formation in the deep part of the pit.

\section{Declarations}

\section{Acknowledgement}

This study was in part supported in part by the Science and Technology Planning Project of Fujian Province, China(2019H0015), and in part by the Subsidized Project for Postgraduates' Innovative Fund in Scientific Research of Huaqiao University (18014080007).

\section{References}

1. He YZ, Li MC, Meng ZQ et al. (2021) An overview of acoustic emission inspection and monitoring technology in the key components of renewable energy systems. Mechanical Systems and Signal 
2. Al-Obaidi SMA, Leong MS, Hamzah RIR et al. (2012) A Review of Acoustic Emission Technique for Machinery Condition Monitoring: Defects Detection \& Diagnostic. Applied Mechanics and Materials 229231:1476-1480

3. Jayakumar T, Mukhopadhyay CK, Venugopal S et al. (2005) A review of the application of acoustic emission techniques for monitoring forming and grinding processes. Journal of Materials Processing Technology 159:48-61

4. Elasha F, Greaves M, Mba D et al. (2017) A comparative study of the effectiveness of vibration and acoustic emission in diagnosing a defective bearing in a planetry gearbox. Applied Acoustics 115:181195

5. He KF, Li XJ, Li XC (2010) Research on feature extraction experiment for acoustic emission signal of rotor crack fault. Applied Mechanics \& Materials 34-35:1005-1009

6. Zhang X, Feng NZ, Wang Y et al. (2015) Acoustic emission detection of rail defect based on wavelet transform and Shannon entropy. Journal of Sound and Vibration 339:419-432

7. Lei RD, Zhang ZY, Berto F et al. (2020) Cracking process and acoustic emission characteristics of sandstone with two parallel filled-flaws under biaxial compression. Engineering Fracture Mechanics 237:107253

8. Elforjani M, Mba D (2010) Accelerated natural fault diagnosis in slow speed bearings with Acoustic Emission. Engineering Fracture Mechanics 77:112-127

9. Gao ZY, Wang XF, Lin J et al. (2017) Online evaluation of metal burn degrees based on acoustic emission and variational mode decomposition. Measurement 103:302-310

10. Liang XL, Liu ZQ, Yao GH et al. (2019) Investigation of surface topography and its deterioration resulting from tool wear evolution when dry turning of titanium alloy Ti-6Al-4V. Tribology International 135:130-142

11. Siwawut S, Saikaew C, Wisitsoraat A et al. (2018) Cutting performances and wear characteristics of WC inserts coated with TiAISiN and CrTiAlSiN by filtered cathodic arc in dry face milling of cast iron. International Journal of Advanced Manufacturing Technology 97:3883-3892

12. Imran M, Mativenga PT, Gholinia A et al. (2014) Comparison of tool wear mechanisms and surface integrity for dry and wet micro-drilling of nickel-base superalloys. International Journal of Machine Tools and Manufacture 76:49-60

13. Maia LHA, Abrao AM, Vasconcelos WL et al. (2015) A new approach for detection of wear mechanisms and determination of tool life in turning using acoustic emission. Tribology International 
14. Deja M, Zieliński D (2020) Wear of electroplated diamond tools in lap-grinding of Al2O3 ceramic materials. Wear 460-461:203461

15. Zhou J, Zhang J, Zhou H et al. (2021) Wear characteristics of diamond segments on multi-blade combination saw with different diameters in granite sawing. International Journal of Refractory Metals and Hard Materials 97:105517

16. Gowthaman PS, Jeyakumar S, Saravanan BA (2020) Machinability and tool wear mechanism of Duplex stainless steel - A review. Materials Today: Proceedings 26:1423-1429

17. Ai YT, Guan JY, Fei CW et al. (2017) Fusion information entropy method of rolling bearing fault diagnosis based on n-dimensional characteristic parameter distance. Mechanical Systems \& Signal Processing 88:123-136

18. Luo SY, Liao YS, Chou CC et al. (1997) Analysis of the wear of a resin-bonded diamond wheel in the grinding of tungsten carbide. Journal of Materials Processing Technology 69:289-296

19. Ma Y, Yang J (2015) Multi-sensor intelligent monitoring of high-speed grinding for brittle and hard materials. Applied Mechanics and Materials 741:309-314

20. Rmili W, Ouahabi A, Serra R et al. (2016) An automatic system based on vibratory analysis for cutting tool wear monitoring. Measurement 77:117-123

21. Li XL (2002) A brief review: acoustic emission method for tool wear monitoring during turning. Int J Mach Tool Manu 42:157-165

22. Kerkwijk B, Mulder E, Verweij H (1999) Zirconia-alumina ceramic composites with extremely high wear resistance. Advanced Engineering Materials 1:69-71

23. Ai YT, Guan JY, Fei CW et al. (2017) Fusion information entropy method of rolling bearing fault diagnosis based on n-dimensional characteristic parameter distance. Mechanical Systems and Signal Processing 88:123-136

24. Cooley JW, Tukey JW (1965) An algorithm for the machine calculation of complex Fourier series. Mathematics of computation 19:297-301

25. Lopes WN, Junior POC, Aguiar PR et al. (2021) An efficient short-time Fourier transform algorithm for grinding wheel condition monitoring through acoustic emission. The International Journal of Advanced Manufacturing Technology 113:585-603

26. Gokhale MY, Khanduja DK (2010) Time domain signal analysis using wavelet packet decomposition approach. International Journal of Communications Network \& System Sciences 3:321-329 
27. Stancu AG, Zhou L, Soua S (2019) Acoustic emission-based similarity analysis: a baseline convergence algorithm. Procedia Structural Integrity 17:238-245

28. Ning F, Pai PS, Mosquea S (2011) Effect of tool edge wear on the cutting forces and vibrations in high-speed finish machining of Inconel 718: an experimental study and wavelet transform analysis. International Journal of Advanced Manufacturing Technology 52:65-77

29. Yen GG, Lin K (2000) Wavelet packet feature extraction for vibration monitoring. IEEE Transactions on Industrial Electronics 47:650-667

\section{Figures}

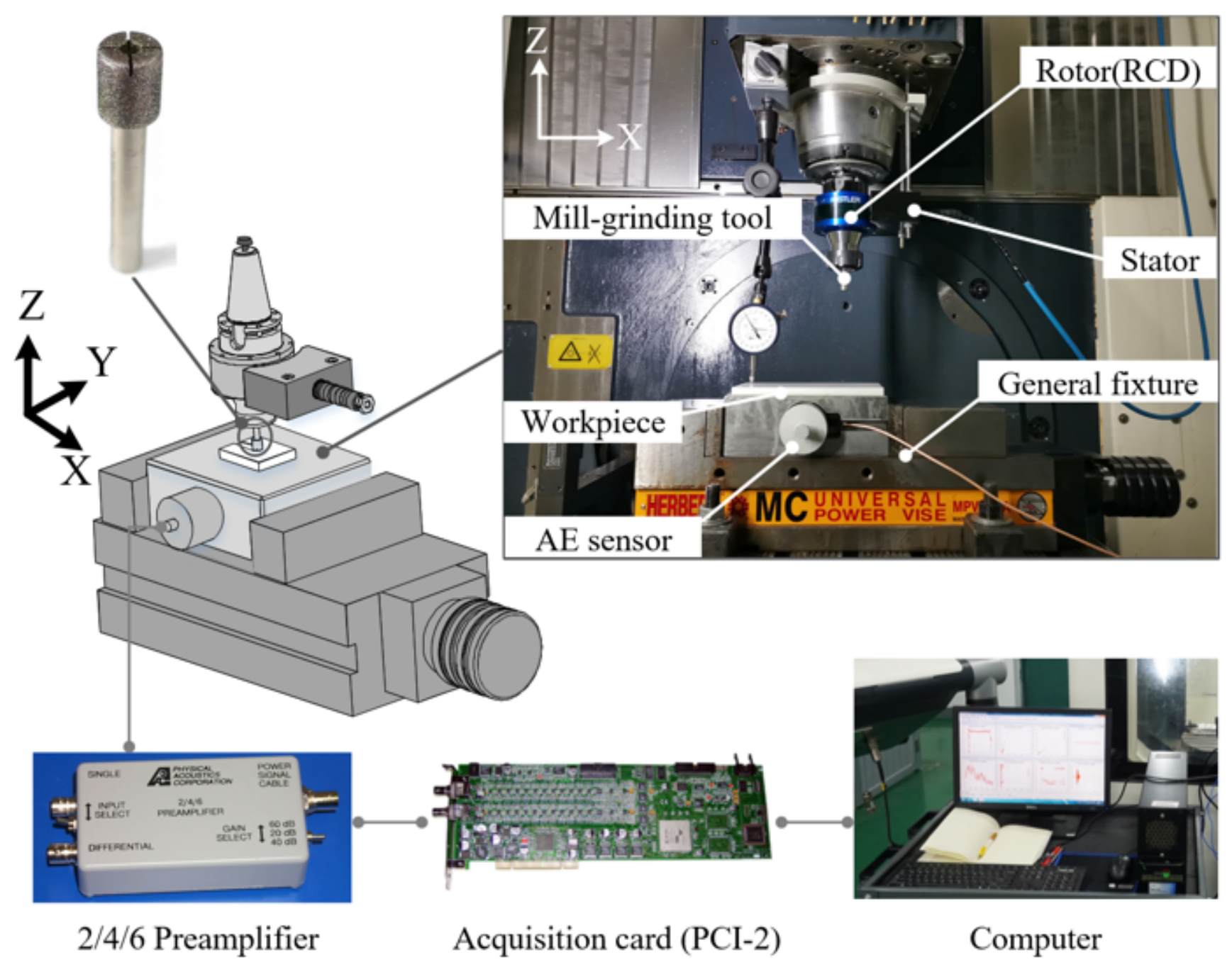

Figure 1

Schematic diagram of experiment 


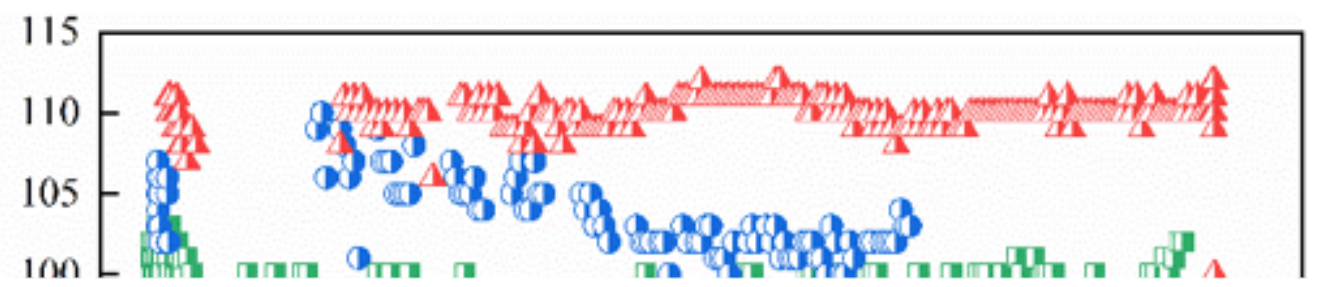

Figure 2

Distribution of acoustic emission amplitude at each impact point at different wear stages 


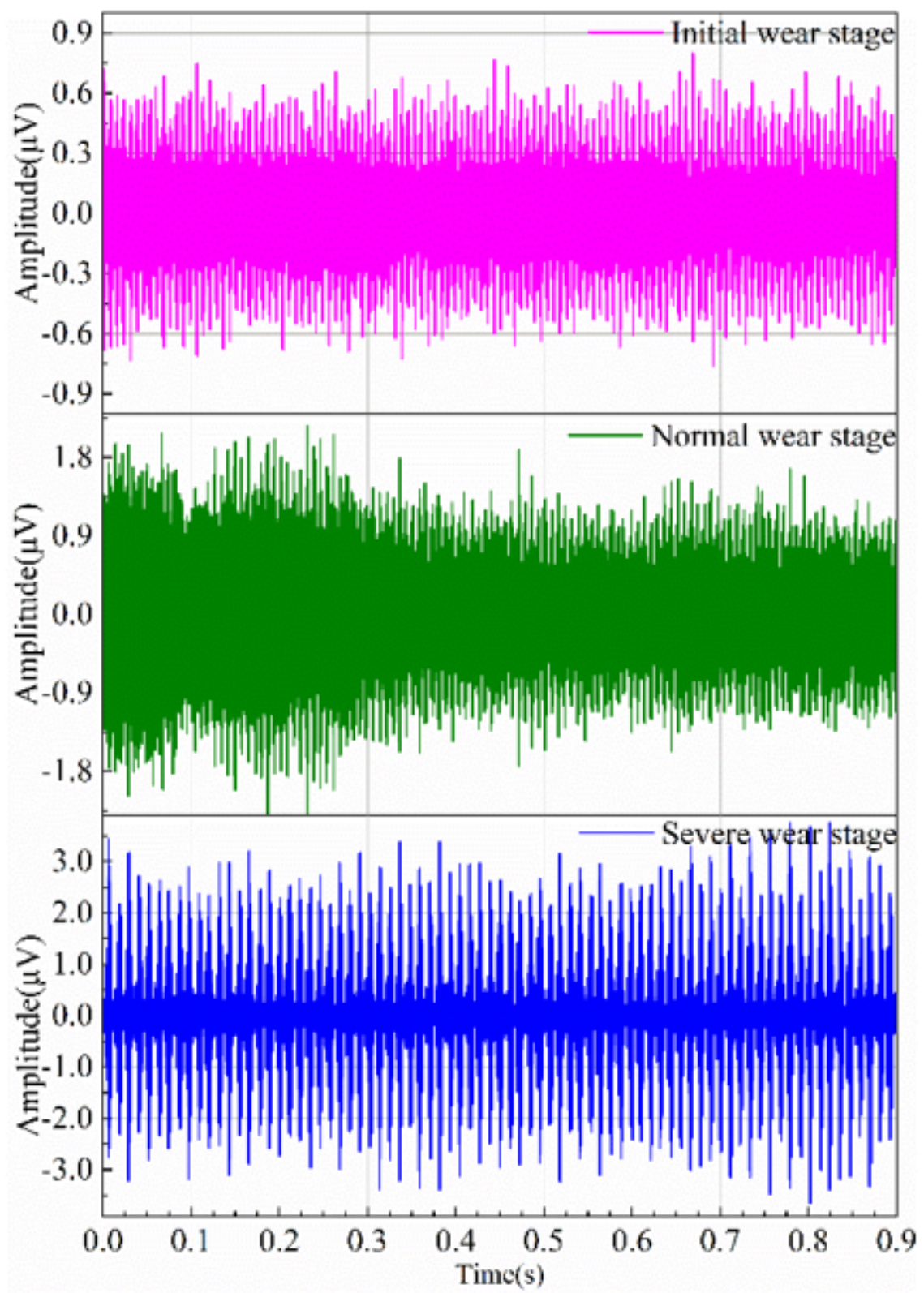

Figure 3

Time domain waveform of acoustic emission signal in different wear stages 


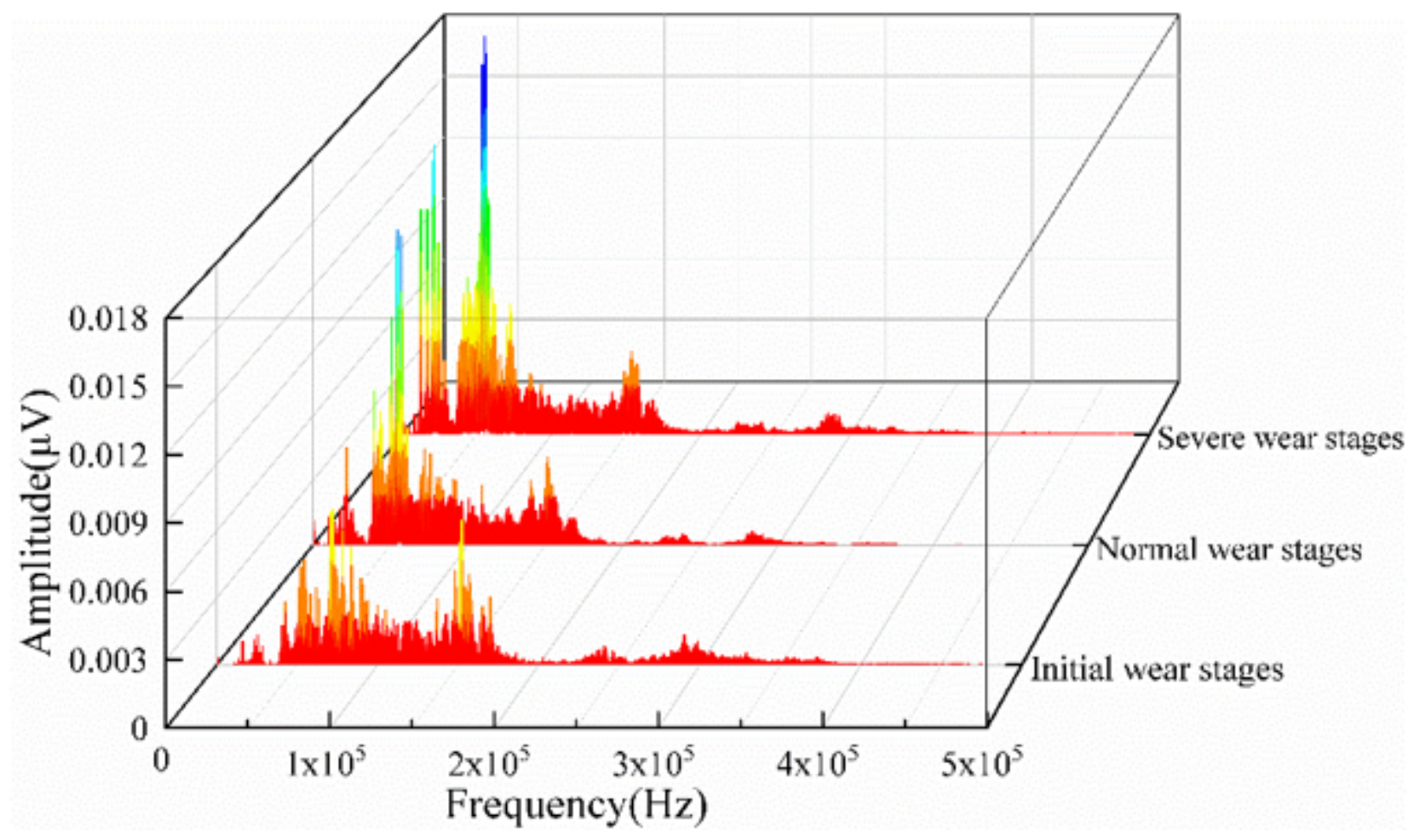

Figure 4

Frequency spectrum comparison of acoustic emission signal in different wear stages 


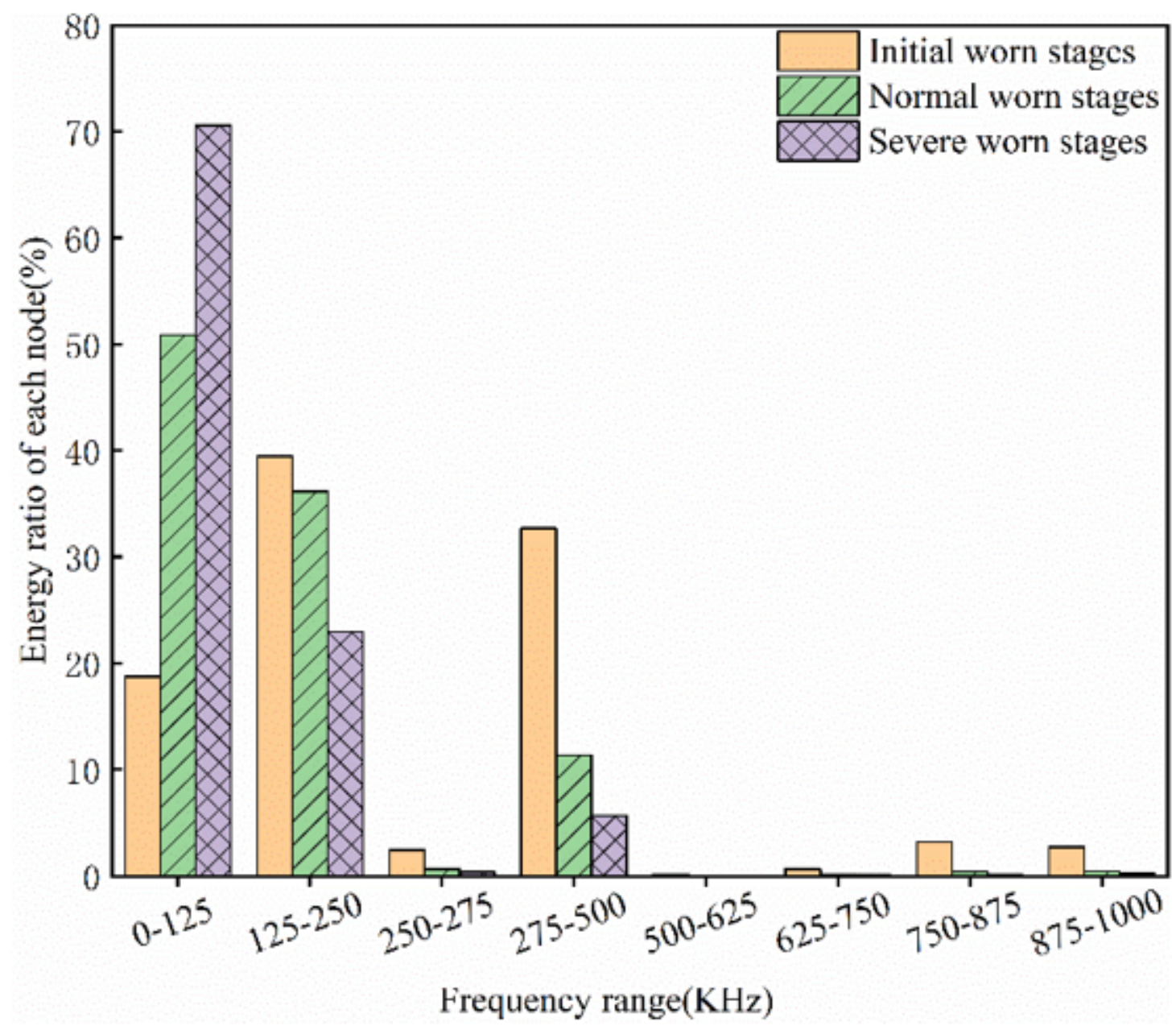

Figure 5

Comparison chart of wavelet packet energy ratio in each frequency band 

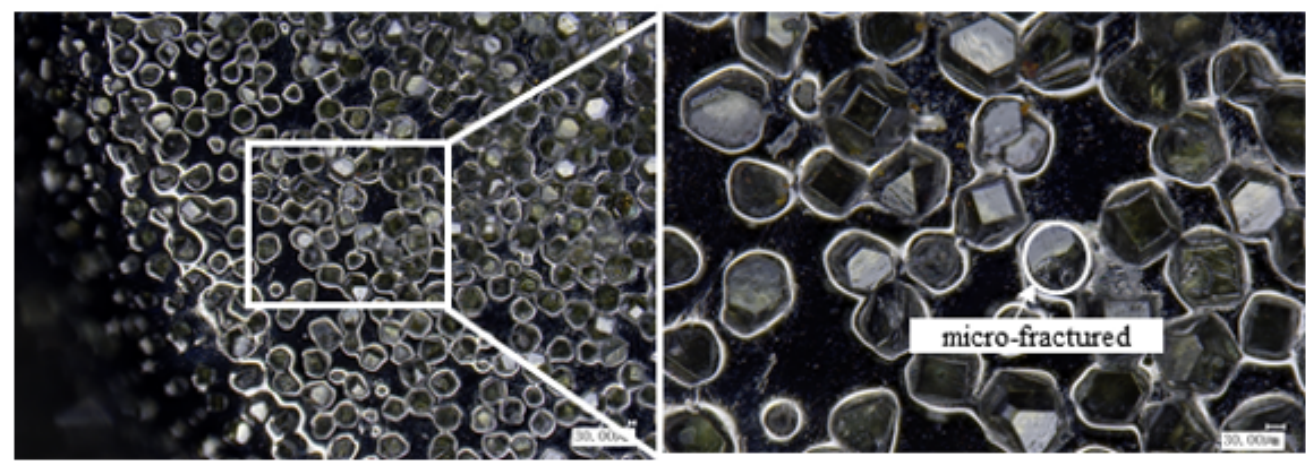

(a) Initial wear stage

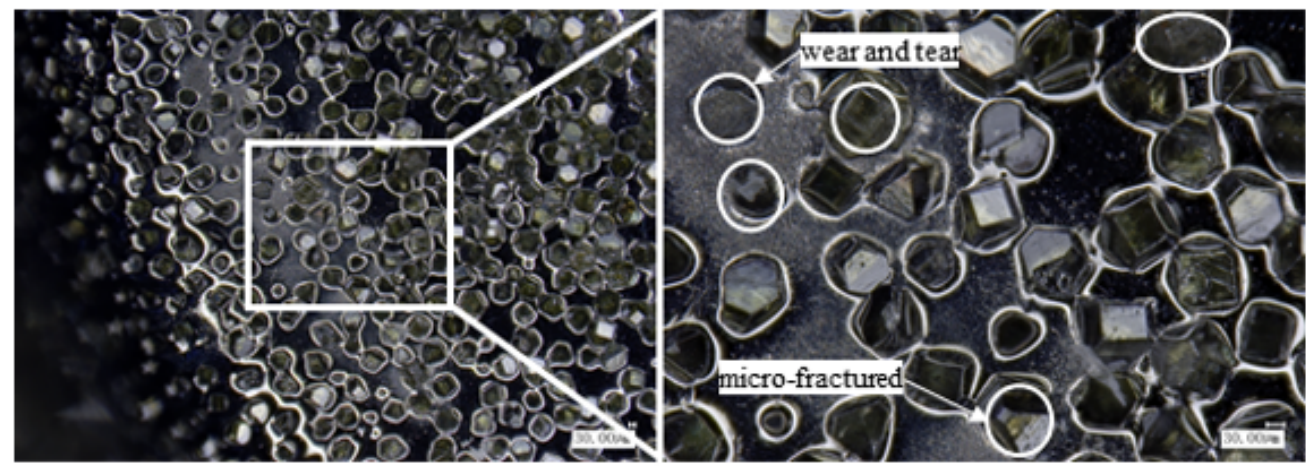

(b) Normal wear stage
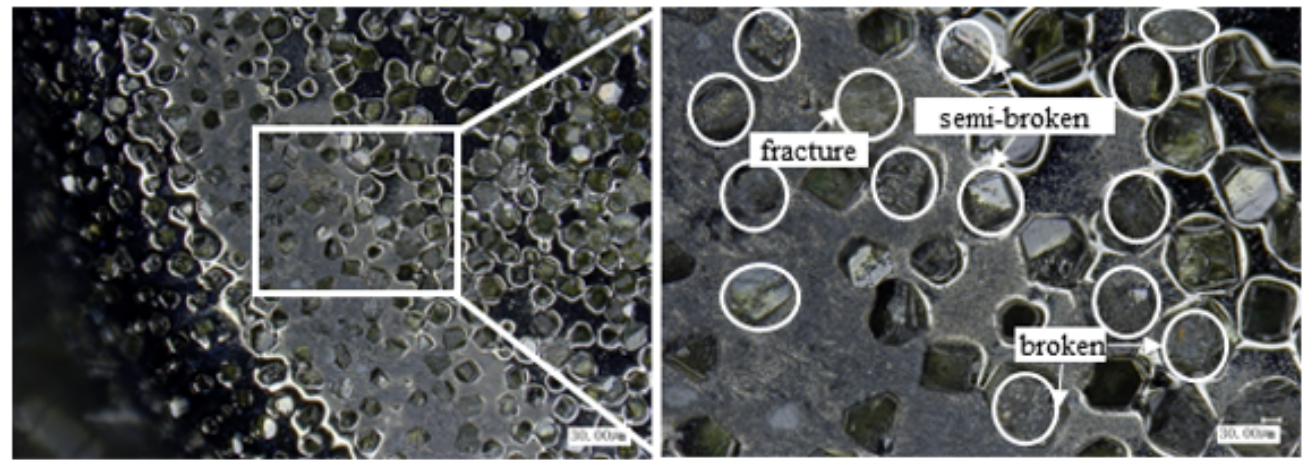

(c) Severe wear stage

Figure 6

Comparison of electroplated diamond milling tools in different wear stages 

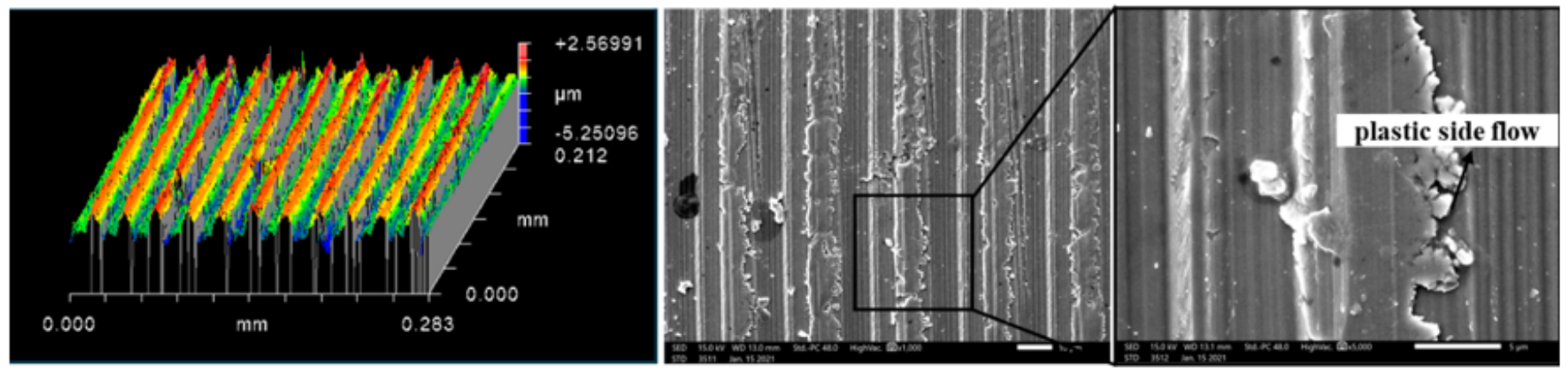

(a) Initial wear stage
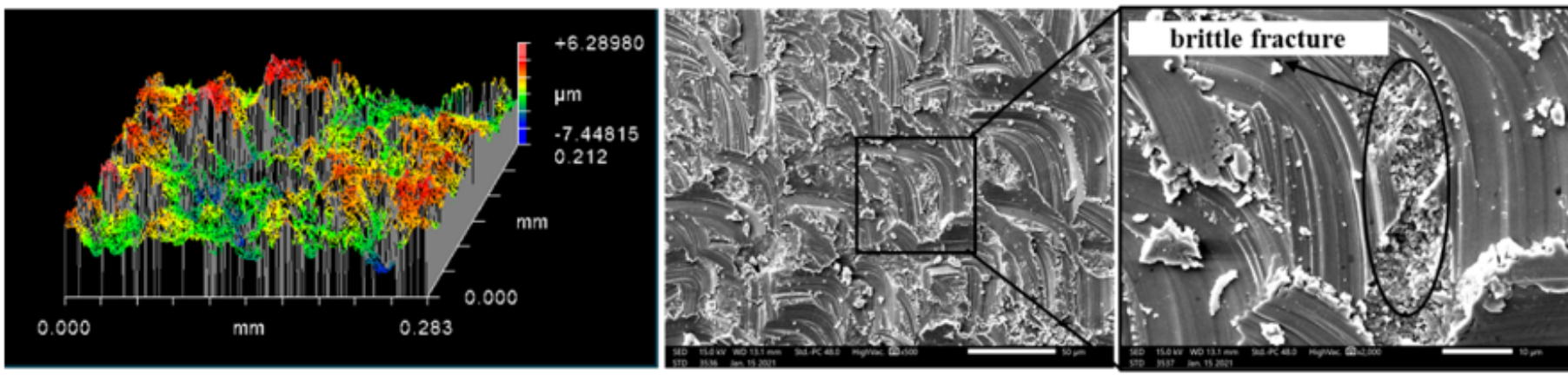

(b) Normal wear stage
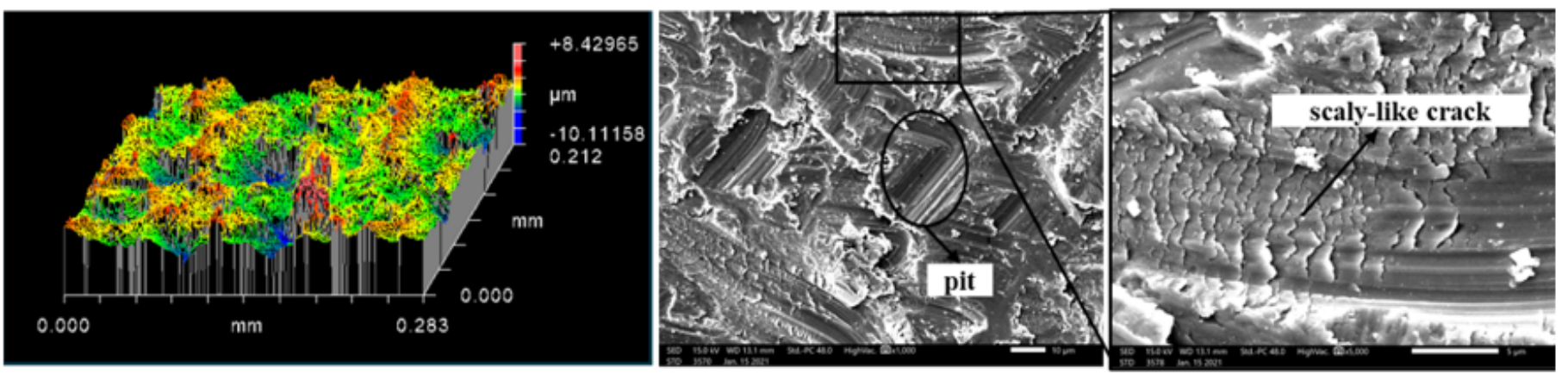

(c) Severe wear stage

Figure 7

Surface morphology of workpiece in different wear stages 